\title{
ROBERTO JUARROZ O LA REHUMANIZACIÓN DE UNA POESÍA TAN VERTICAL COMO LA PROPIA VIDA
}

Miguel Zugasti

Universidad de Navarra

«Hacia la voz del Hombre»

César Vallejo

Corren tiempos dificiles para la poesia. Dentro del restringido campo de la creación literaria no es arriesgado calificarla como la pariente pobre de nuestras letras contemporáneas. Ante la pujanza del sin duda género rey, la novela, no es de extrañar que muchos poetas acaben convirtiéndose en narradores después de varias intentonas editoriales. En este sentido el argentino Roberto Juarroz se erige como un paladín de la figura clásica del poeta constante, unitario, dedicado por entero al ejercicio de su oficio a la manera de Petrarca, Garcilaso, Góngora, Neruda, Aleixandre y tantos otros. Sus poemas, de una absoluta contemporaneidad, cargados de conocimiento y experiencia vitales, adoptan el revestimiento de un lenguaje puro, comunicativo al máximo, dando de lado a la poesía experimental tan en boga últimamente. Por firme convicción estética evita con cuidado hermetizar el lenguaje de sus textos e incurrir en el fácil error de equiparar oscuridad a calidad. No secunda la línea de algunos autores que experimentan con palabras como si de números se tratasen, que rompen la sintaxis o la semántica de la lengua hasta rozar el límite de lo inconexo e incomprensible. (Todo lo cual puede ser positivo siempre y cuando el poeta esté por encima de dicho procedimiento o técnica disociadora - tal es el caso de muchas composiciones del mejor Lorca, Huidobro, Cernuda...- y no al revés).

Con Roberto Juarroz el lector se interna en una poesía donde se recupera el poder mágico de la palabra que transmite y comunica algo y que cala 
hondo en su percepción. $\mathrm{Al}$ adentrarse en la "aventura poética»' de Juarroz se tiene la sensación de estar junto a un arte rehumanizado, de haber reencontrado la voz del hombre, de hallarse ante una obra viva y personal que existe por sí misma desde el principio. Y así es, en efecto, pues desde la aparición de su primer libro (Poesía vertical, Buenos Aires, Equis, 1958) todos los elementos convergen hacia la creación de un mundo particular y concreto, hacia la exposición de una idea poética sólida, unitaria y en continuo avance. Prueba irrefutable de esta progresión es que el autor mantiene idéntico título para el resto de sus poemarios, con la leve variante de la inclusión del sucesivo orden numérico con que los va entregando a las prensas. De este modo irán poco a poco apareciendo su Segunda poesia vertical, Tercera..., Cuarta..., etc. De la misma manera tampoco titulará sus poemas por separado, sino que se limita a disponerlos numéricamente.

Merece la pena destacar que la mayoría de sus páginas han sido traducidas al ínglés y al francés, en cambio el conocimiento del poeta argentino en España ha sido mucho más tardío y también menos intenso por lo que a la edición de sus obras respecta. Su primer libro, una breve antologia, ve la luz en el año $1974^{2}$. Tuvieron que pasar trece años para encontrarnos con una segunda selección de sus escritos ${ }^{3}$, y poco más tarde se publica un tercer poemario -el cual ya no será una antología sino un libro completo -, logrando así lo que podria definirse como la mayoría de edad de Roberto Juarroz dentro del mercado editorial español. No obstante, anteriores a estas publicaciones o simultaneándose con ellas, cabe reseñar también la existencia de otros fragmentos mínimos de la obra juarrociana que vieron la luz en distintas revistas del país. Todavía en 1972 el escritor bonaerense era «el desconocido de Maldoror»", pero poco más tarde su nombre aparece inscrito dentro de la antología de poetas argentinos que realizó José Alberto Santiago ${ }^{6}$. En 1983 encontramos en la revista plurilingüe Equivalencias algunos de sus versos traducidos al inglés por Louis Bourne?. Al año siguiente Juarroz vuelve a ocupar su justa plaza en una nueva antología, esta vez de la poesía hispanoamericana en su conjunto ${ }^{8}$. En 1985, precedidos por un estudio crítico

1 Tomo la expresión del trabajo de RodRíguez PADRON, Jorge, "La aventura poética de Roberto Juarroz", Nueva Estafeta, núm. 54, mayo 1983, pp. 47-54.

${ }^{2}$ Poesía vertical, Barcelona, Barral, col. Ocnos, núm. 46, 1974.

${ }^{3}$ Poesía vertical. Antología incompleta, selección y prólogo de Louis Bourne, Madrid, Playor, 1987.

4 Undécima poesia vertical, Valencia, Pre-Textos, 1988.

5 Título con el que un sagaz periodista cubría la noticia de ciertos problemas dentro del jurado a la hora de fallar el premio Maldoror de poesía de ese año.

- Antologia de la poesía argentina, ed. José Alberto Santiago, Madrid, Editora Nacional, 1973, pp. 443-446.

7 Equivalencias, Madrid, núm. 7, 1983.

- Antologia de poesia hispanoamericana (1915-J980), ed. Jorge Rodríguez Padrón, Madrid, Espasa-Calpe, 1984. 
de Francisco Rivera, salen a la luz nuevos poemas suyos?. De 1988, además del libro citado en la nota 4 , datan dos nuevas calas juarrocianas: un poema escrito en homenaje a César Vallejo y un breve avance de algunas composiciones del hasta ahora su último libro: Undécima poesía vertical ${ }^{10}$.

En el prólogo que Louis Bourne escribe para la Poesía vertical. Antología incompleta (a partir de ahora citaré de forma abreviada, $P V A I$, transcribo igualmente la Undécima poesía vertical como $11 P V$, pues va a ser sobre estos dos títulos donde basaré mis asertaciones) se declara que el libro ha sido dividido en once capítulos o secciones - cuyos epígrafes han sido extraídos por el antólogo de distintos versos del mismo Juarroz-- que responden a otros tantos temas nucleares de la poética juarrociana. Los once temas (junto a sus opuestos) son los siguientes: la vida, la muerte, el cuerpo, la caída, la mirada, la palabra (y el silencio), la ausencia (y la presencia), la memoria (y el olvido, el sueño, el vacio), la luz (y la sombra), el amor (y la soledad) y el pensamiento. Como ya se ha dicho más arriba, toda la obra del poeta argentino transcurre en una misma dirección; toda ella forma un conjunto de partes perfectamente ensambladas que se refieren a un número relativamente corto de temas. Uno de sus más altos valores reside en la visualización de estos temas desde diferentes ángulos, de tal manera que cada uno de estos tópicos podría equipararse a un poliedro de múltiples caras donde cada cara representaría el distinto punto de vista del autor materializado en cada nuevo poema. Un poeta como Juarroz tan poco dado a la diversidad temática pero a la vez tan prolijo, sólo puede ser fecundo si, como él hace, concibe la escritura como algo continuo e ininterrumpido que versa sobre la vida y sus mil manifestaciones, sobre el hombre y sus infinitas complejidades. Él escribe un «poema continuo» sobre la vida y las cosas del entorno, pues «cada cosa es una letra,/un signo de puntuación,/la inflexión de una frase». Para él:

La poesía se escribe siempre,

vivir se vive siempre,

algo despierta siempre:

poema-siempre.

El ser es escritura. (IIPF, p. 38)

"Roberto Juarroz o el descenso a las profundidades", Cuadernos núm 420, junio 1985, pp. 91-105. A este ensayo le sucede, en el mismo ericanos, num quince poemas de la Poesía vertical, en pp. 106-116.

cluido en volumen homenaje que se le dedicó al autor peruano en de poemas fue publicado por esta misma revista, núm. 459 , septiembre 1988, pp. 31-38. Por otra parte conviene destacar que se han hecho dos ediciones simultáneas de la Undécima poesía vertical, una en España y otra en Argentina, Buenos Aires, Carlos Lohlé, 1988. 
Entiéndase por tanto que para Juarroz el acto de escribir no es volitivo; muy al contrario es algo que se lo dicta su propia existencia. Y como la existencia de cada día es distinta, sus poemas - aunque traten sobre un corto abanico de temas- no son repeticiones, sino variaciones o complementaciones de esa realidad que todas las mañanas aparece ante nuestros ojos de distinta manera, con otra perpectiva. Sabido esto, lógico es deducir que su última entrega, Undécima poesía vertical, no supone grandes novedades en su producción, sino que bien al contrario responde al esperado avance unidireccional de su corpus poético. (No obstante sí se puede resaltar que toda la tercera parte del libro insiste de forma muy peculiar en un tema novedoso: el asombro.) No sería pertinente en el caso de Juarroz analizar sus volúmenes por separado, ello más bien supondría una falla en la propia base del análisis.

Esta unidad dimensional de la poesía juarrociana no significa ausencia de dudas tensiones o contradicciones; el lector atento se percata casi de inmediato de que los dos ejes sobre los que gira su arte poético - la realidad material y el hombre como ser pensante- mantienen entre sí un pulso continuo. La existencia de las cosas materiales da origen a la realidad que nos rodea, pero el poeta sabe que esas cosas son incompletas y por lo tanto lo que visualizamos es fragmentario. El hombre, en la medida de sus posibilidades, debe completar esa realidad para dar así mayor sentido a la vida. A este respecto el propio autor gusta citar a Paul Klee cuando dice que lo visible es sólo un ejemplo de lo real ${ }^{11}$. La labor del hombre-poeta consiste en producir nuevos ejemplos de lo real, es decir: crear: El poeta es aquella persona que toma máxima conciencia de esto y consagra sus esfuerzos a la creación de su propia realidad.

Este deseo de trascender lo puramente visible es lo que provoca en Juarroz el duro pulso entre realidad/hombre antes mencionado, un pulso que se mantiene siempre erguido, vertical. Tal y como define Louis Boume en su excelente prólogo, «la verticalidad de su poesía tiene que ver con un movimiento por encima y debajo de la línea horizontal de la existencia acostumbrada» ${ }^{12}$.

"Cf. Zugasti, Miguel, "Voice of the poets: Roberto Juarroz and César López on poetry", Hispanic Horizon, New Delhi, núms. 6-7, winter 1988-monsoon 1989, pp. 67-71.

${ }_{12} \mathrm{El}$ prólogo, un análisis de un poeta por otro poeta, lleva el siguiente título: «Un buceador en el trasfondo del ser", pp. 9-29. La cita está extraida de la p. 10. Es muy de agradecer la recopilación bibliográfica que realiza $\mathrm{L}$. Bourne en pp. 30-33, facilitando así la tarea de aproximación critica a Juarroz. Cabe mencionar la ausencia del trabajo de Miguel CABRERA («La poesía vertical de Roberto Juarroz», Nueva Estafeta, núm. 47, octubre 1982, pp. 77-78) que en nada empaña la tarea de rebusca hecha por el antólogo. Si para editar un repertorio bibliográfico habría que esperar a tener la certeza de que no existen huecos posibles, entonces éste nunca llegaría a ver la luz. Añádanse, hasta donde yo conozco, como entradas posteriores mi trabajo citado en la nota anterior, otro de ABEL FofFANI, Enrique, «La poesía de Roberto Juarroz y el Oriente: la otra lógica», Cuadernos Hispanoamericanos, núm. 471, septiembre 1989 , 
Hay una tensión vertical siempre latente entre lo posible y lo real, lo vacío y lo lleno, lo teórico y lo práctico. La obra de Juarroz tiene la gran virtud de bucear en el ser humano hasta lograr unir estos dos polos, al igual que los antiguos poetas griegos o los del budismo zen fusionaban en el poema sus ideas de poesía y filosofia. Esto significa salirse de lo acostumbrado, de lo mediocre, de la idea plana, aunque ello implique adoptar la vía de la tensión, de la duda o de la lucha con uno mismo.

Pero también implica otra cosa, y es que sus temas preferidos - como ya antes he apuntado - contienen siempre a sus inmediatos opuestos. Juarroz nunca habla de la vida sin incluir en el verso siguiente a la muerte, nunca menciona al hombre sin situarlo en medio de las cosas, no puede referirse al amor sin dar cabida al olvido o a la soledad, y así sucesivamente. En un mismo poema incluye los dos contrarios; unas veces los complementa o armoniza, pero otras veces - las más de ellas - los enfrenta o anula entre sí. Ahora bien, ¿cómo combina el autor estos elementos contradictorios en el poema? ¿Los va enumerando de forma discursiva? ¿Los coloca en bloques antagónicos que se oponen desde el principio hasta el fin? Ni lo uno ni lo otro. Responder a estos cuestionamientos nos llevará al quid de la poesía juarrociana, pues hay que analizar el proceso mismo de escritura del poema, la lucha diaria del autor con las palabras; hay que intentar meterse en la piel del verso y desentrañar así el verdadero quehacer poético. Si llegamos a aprehender cómo está construido el poema, podremos entender más fácilmente qué dice. Me estoy refiriendo a la estructura poemática, la cual podrá ser la clave interpretativa de la obra que nos ocupa.

Empezando por la unidad estructural más elemental, el verso, es preciso observar cómo el autor gusta de hacer juegos o transposiciones del lenguaje a base de utilizar una palabra en positivo y de inmediato volver a emplearla en negativo. Los ejemplos que se podrian aducir se cuentan por docenas; he aquí algunos:

Yo no tengo más tiempo que el que nunca fue tiempo. (PFAI, p. 36).

Como ser la conciencia y la inconciencia. (PFAI, p. 47).

El tiempo se convierte en antitiempo. (PFAI, p. 64).

El secreto de no amar lo que amamos. (PFAI, p. 130).

Toda nuestra verdad es no tenerla. (PFAI, p. 139).

pp. 146-152, y por último el muy reciente de MALPARTIDA, Juan, "La perfección indefensa», Cuadernos Hispanoamericanos, núm. 480, junio 1990, pp. 45-51. 
Sigue lloviendo sin la lluvia. (PFAI, p. 170).

Lo posible es sólo una provincia de lo imposible. (IIPF, p. 43).

Silencio sin silencio. (IIPF, p. 50).

Toda negación es una afirmación. (IIPF, p. 120).

Hay que abrir paréntesis de no ser en el ser. (IIPF, p. 126).

Aquí tenemos un atisbo bastante representativo de la manera en que Juarroz entrelaza y contrapesa conceptos discordantes. Ya en este corto muestreo se aprecia la técnica de inversión de signos a base de enunciar o afirmar primero un concepto o idea cualquiera y en segundo lugar pasar directamente a su negación. Para ello el poeta se servirá de abverbios como no y nunca, de las preposiciones sin, contra y de prefijos tales como in-, antio el nec- latino. El resultado final es que nos encontramos muchas veces ante una paradoja, ante una sentencia que aúna por sí misma pensamientos antitéticos.

Subiendo un escalón más en el edificio del poema se advierte con igual nitidez cómo nuestro autor insiste en su particular estilo de mencionar conjuntamente elementos opuestos dentro de un número corto de versos, los cuales pueden formar una estrofa completa o bien sólo una parte. Veamos algún ejemplo:

Una palabra es todo el lenguaje, pero es también la fundación de todas las transgresiones del lenguaje, la base donde se afirma siempre un antilenguaje. ( $P F A I$, p. 118)

Son muchas las presencias que deben disolverse para hacer una ausencia que quepa entre las manos. (PFAI, p. 135)

A través del texto, que sin embargo no está terminado, leo todos los otros.

$\mathrm{O}$ tal vez es ese texto el que los lee. (IIPF, p. 25) 
Tal vez quiera leer

lo que no se puede escribir.

O simplemente lo que no se puede leer, aunque se escriba. (IIPF, p.37)

Pero el poeta no sólo opta por incluir en un simple verso o en una estrofa los dos o mil polos de su pensamiento, sino que además procura que la estructura de tal verso o tal estrofa refleje esa tensión semántica a que están sometidas las palabras. De aquí procede el abundante uso de construcciones en quiasmo que le sirven perfectamente al autor para aumentar en muchos enteros esa sensación de que las ideas discurren por un interminable camino de ida y vuelta, de saltos adelante y atrás:

Porque no somos nosotros los que miramos las palabras: son ellas las que nos miran a nosotros. (PFAI, p. 111)

Algunos silencios generan pasos y algunos pasos engendran silencios. (IIPF, p.71)

A esta misma función obedece el también frecuente empleo de paralelismos y simetrías (o asimetrías) perfectas:

La vida dibuja un árbol y la muerte dibuja otro. La vida dibuja un nido y la muerte lo copia. La vida dibuja un pájaro para que habite el nido y la muerte de inmediato dibuja otro pájaro. (PFAI, p. 40)

La sombra deslumbra más que la luz.

La noche, más que el día.

También el silencio deslumbra más que la palabra.

¿Acaso la muerte deslumbrará más que la vida? (IIPF, p. 91) 
Inclusa puede darse el caso de que en una misma estrofa se combinen ambos prodecimientos:

Hablar es vivir de otra manera, pero también morir de otra manera, como si vivir fuera morir, como si morir fuera vivir. (PFAI, p. 133)

Continuando nuestro análisis llegamos ya al estadio final que es la visión del poema como conjunto y unidad estructural cerrada. En su trabajo antes citado, Miguel Cabrera habla de los tonos «explicativo» y «deductivo» de gran parte de las composiciones que dan lugar a una ordenación poemática casi fija, en la cual la gradación imperante es: Estrofa planteamiento + Estrofa extensión + Estrofa conclusión. Sin poder asentir categóricamente con esta conjetura, sí es digno de señalar que en muchos poemas se repite un esquema constructivo que da la impresión de haber logrado un equilibrio y una solidez perfectas. Generalmente los juegos de simetrías, asimetrías, paralelismos, anáforas, epiforas, etc., se concentran en las primeras estrofas formando un bloque conjunto y compacto. Pero es justo en los últimos versos o en la estrofa de cierre donde se produce el típico desajuste juarrociano que provoca la situación paradójica o antitética que arrasará con todo lo expuesto más arriba. Es la última vuelta de tuerca de una idea que desbarata la anterior oposición de bipolaridad y unifica en un todo o disuelve en la nada (cualquiera de las dos vías es propia de Juarroz) lo que hasta entonces era aparentemente contrario. Estos versos finales, no exentos de cierto tono sentencioso o aforístico, suponen el máximo climax a que está sometido el pensamiento, la penetración última en una idea que busca siempre la salida más insospechada. El resultado final es la duda constante, una suerte de vértigo o perplejidad a la que el lector no podrá sustraerse:

El árbol es una lección de presencia, una lección sin precedentes, donde se reúnen como en una dimensión o tiempo o ejemplo distinto las preguntas del recuerdo $y$ las preguntas del olvido. 
La canción en cambio es siempre

una forma de la ausencia,

un eco del polvo que se levanta

en lugar de la palabra que no existe.

Pero no sólo es una magia la presencia:

también es una magia la ausencia.

Por eso el árbol y la canción estarán siempre juntos,

aunque el invierno abata las palabras y las hojas. (PVAI, p. 110)

Una invasión de palabras

trata de acorralar al silencio,

pero, como siempre, fracasa.

Intenta luego arrinconar a las cosas

que habitan el silencio,

pero tampoco lo consigue.

$Y$ va por fin a cercar a las palabras

que conviven con el silencio,

pero entonces se produce lo imprevisto:

el silencio se convierte en palabra

para proteger mejor a las palabras

que conviven con él.

Y mientras la invasión de las otras palabras

se desvanece como un soplo furtivo,

se completa lo insólito:

las palabras que quedan

se asemejan ahora mucho más al silencio

que a las otras palabras. (IIPF, p. 63)

Roberto Juarroz somete al intelecto a la máxima concentración y consigue crear una poética tan personal como ambiciosa. Concibe la creación como un acto de totalidad cuya meta es abarcar lo real de la vida hasta el extremo de sus posibilidades. Tiene la valentía de escribir una poesía profunda, metafisica, que vuelve a deternerse (como ya lo hicieran S. Mallarmé, T. S. Eliot, R. M. Rilke o M. de Unamuno) en la esencia del hombre y de su existencia. Pero este afán de absoluto conlleva el riesgo de que el autor no siempre logre alcanzar la meta que se ha propuesto. La ambición (o necesidad) de escribir una poesía de estas características supone una cierta descompensación en la balanza, pues mientras se explota continuamente el aspecto intelectual o mental, queda un tanto huérfano el campo sentimental o emotivo. Otro riesgo del que Juarroz no siempre sale bien librado es el de caer en la inercia de multiplicar ad nauseam las preguntas y los giros de tal forma que la única vía de escape sea una respuesta antitética. Aunque en la mayoria de los casos las paradojas y antinomias son reflejo de una meditación y de una lógica personalisimas, ello no obsta para que alguna 
vez (ver por ejemplo el poema de la p. 137 en $11 P F$ ) el poeta se haya dejado llevar por lo lúdico del juego de palabras y la inevitable oposición de contrarios, antes que por su criticismo y raciocinio. Pero la libertad y coraje con que asume estos riesgos, el compromiso interno con que rige el acto creativo y la profunda honestidad con que manifiesta su yo íntimo, convierten a Roberto Juarroz no ya sólo en una figura estelar de la poesía argentina, sino también en uno de los mas firmes baluartes con que cuenta hoy en día la poesía escrita en castellano. 